\title{
Protein expression, mRNA expression and gene amplification of DNA methyltransferase 1 in endometrial tumor tissues
}

\author{
SATOSHI IKEDA ${ }^{1}$, JOHJI IMURA ${ }^{2}$ and KEIKO SUZUKI ${ }^{1}$ \\ ${ }^{1}$ Department of Pathology, Tsuchiura Kyodo General Hospital, Ibaraki 300-0053; ${ }^{2}$ Department of Diagnostic Pathology, \\ Graduate School of Medicine and Pharmaceutical Science, University of Toyama, Toyama 300-0053 Japan
}

Received August 4, 2012; Accepted February 4, 2013

DOI: $10.3892 / \mathrm{mco} .2013 .96$

\begin{abstract}
Inactivation of tumor suppressor genes by methylation is an important pathway in the multi-step process of carcinogenesis. The aim of this study was to investigate the expression of DNA methyltransferase 1 (DNMT1) which strongly contributes to the methylation process in endometrial normal and tumor tissues. Moreover, a correlation with the expression of hMLH1 and E-cadherin that was inactivated in a number of endometrial cancers was observed. Samples were obtained from 8 cases of normal endometrium, 10 cases of hyperplasia, 11 cases of atypical hyperplasia and 38 cases of carcinoma. DNMT1 expression was correlated with tumor progression $(\mathrm{P}=0.0023)$, as well as with the attenuation of hMLH1 and E-cadherin expression $(\mathrm{P}=0.031$ and 0.031 , respectively). No attenuation of hMLH1 and E-cadherin expression was observed in DNMT1-negative cases. Thus, the investigation of DNMT1 expression in clinical samples was shown to be useful in identifying the conditions that are related to general methylation. Overexpression of DNMT1 messengerRNA (mRNA) was mainly observed in carcinomas. Gene amplification occurred with tumor development. Gene amplification of DNMT1 was correlated with the expression of DNMT1 protein $(\mathrm{P}=0.041)$. In conclusion, overexpression of DNMT1 protein is caused by various factors, one of which is gene amplification.
\end{abstract}

\section{Introduction}

Epigenetic alterations are important in carcinogenesis, with methylation of the promoter part of tumor suppressor genes constituting one of the important alterations. Although this mechanism can be detected by methylation-specific poly-

Correspondence to: Dr Satoshi Ikeda, Department of Pathology, Tsuchiura Kyodo General Hospital, 11-7 Manabe-shinmachi, Tsuchiura, Ibaraki 300-0053, Japan

E-mail: isohama2587@proof.ocn.ne.jp

Key words: DNA methyltransferase 1, endometrial cancer, hMLH1, E-cadherin, in situ hybridization merase chain reaction (PCR), it is difficult to perform such an investigation in a general hospital. In addition, observation of methylation is complicated as compared with pathological findings. The representative protein in the DNA methyltransferase (DNMT) family of proteins, which has important roles in the methylation of DNA, is DNA methyltransferase 1 (DNMT1) (1). Methylation of a general tumor can be examined by detecting DNMT1 with immunostaining methods, a procedure that is easily performed in a general hospital and it has been reported that overexpression of DNMT1 protein is correlated with the methylation of tumor suppressor genes (2).

An endometrial carcinoma is representative of hormonaldependent tumors, with endometrioid adenocarcinoma, which arises from endometrial hyperplasia, constituting the most frequently encountered type. Methylation is known to occur at a high frequency in this type of adenocarcinoma. Tumor development has been reported to be correlated with the frequency of methylation (2), although the mechanism has yet to be investigated in detail. Using immunostaining methods, we aimed to investigate the expression of hMLH1 and E-cadherin, which have been reported to be attenuated with tumor development in the endometrium (3), and to determine their correlation with the overexpression of DNMT1. In addition, an in situ hybridization (ISH) method was used to determine whether overexpression of DNMT1 is caused by the expression of messengerRNA (mRNA) and/or gene amplification of DNMT1.

\section{Materials and methods}

Subjects. We examined endometrial biopsy tissues resected from patients examined at the Tsuchiura Kyodo General Hospital (Ibaraki, Japan) from 2001 to 2008. Samples were obtained from 8 cases of normal tissue, 10 cases of cystic or adenomatous hyperplasia, 11 cases of atypical hyperplasia and 38 cases of endometrioid adenocarcinoma. This study was approved by the ethics committee of Tsuchiura Kyodo General Hospital. Informed consent was obtained from all subjects. The tissues were embedded in formalin-fixed paraffin sections, with a formalin fixation time of $<48 \mathrm{~h}$. The age of the examined patients ranged from 19 to 88 years. Histological diagnosis was performed by two pathologists based on the Japanese Classification of Endometrial Carcinoma (4). 
Immunostaining. Deparaffinization was performed using xylene, then the immunostaining process was performed as described. Sections were initially re-hydrated using an alcohol series. For hMLH1 and E-cadherin, heat treatment in a microwave oven was performed in citric acid buffer at pH 6.0 for 15 min, while for DNMT1 heat treatment was performed with an autoclave in target retrieval solution (Nichirei Bioscience, Tokyo, Japan) at $\mathrm{pH} 9.0$ for $15 \mathrm{~min}$. The sections were air-cooled for $20 \mathrm{~min}$, then $\mathrm{H}_{2} \mathrm{O}_{2}$ treatment was performed for $10 \mathrm{~min}$ to inactivate endogenous peroxidase. Anti-hMLH1 mouse monoclonal (ES05, dilution, 1:100; Leica Microsystems, Newcastle Upon Tyne, UK), anti-E-cadherin rabbit polyclonal (dilution, 1:200; Santa Cruz Biotechnology, Inc., Santa Cruz, CA, USA) and anti-DNMT1 mouse monoclonal (60B1220.1, dilution, 1:300; Acris Antibodies GmbH, Herford, Germany) antibodies were added to the sections in a moisture chamber and incubated at room temperature for $3 \mathrm{~h}$. After washing in phosphate-buffered saline (PBS) for $30 \mathrm{~min}$, a polymer method was performed at room temperature with the NovoLink ${ }^{\mathrm{TM}}$ polymer HRP kit (Leica Microsystems, Tokyo, Japan). The post-primary antibody and horseradish peroxidase (HRP)-conjugated polymer in the kit were incubated for $30 \mathrm{~min}$ each, and visualization was carried out with 3,3'-diaminobenzidine. Counterstaining with hematoxylin, as well as dehydration and cover slipping were then performed.

mRNA in situ hybridization. DNMT1 mRNA expression in 8 normal cases, 10 cases with hyperplasia, 11 cases with atypical hyperplasia and 19 cases with carcinoma was investigated. The oligonucleotide probe sequence was 5'-GTTGCA GTCCTCTGTGAACACTGTGG-3', as previously reported by Mizuno et al (5). ISH was performed according to the manufacturer's instuctions, with a modest modification of the digoxigenin (DIG)-tailed probe. Sections were treated for 10 min each with pepsin, $\mathrm{HCl}$, triethanolamine, and acetic acid and then incubated with a DNMT1-specific DIG-tailed probe at $42^{\circ} \mathrm{C}$ overnight. DNMT1 mRNA expression was then detected using the GenPoint kit (Dako, Glostrup, Denmark), with an anti-DIG antibody (dilution, 1:2,500; Roche Diagnostics, Tokyo, Japan) used for the detection of DIG instead of the streptavidin included in the kit.

Chromogenic in situ hybridization. The DNA probe for chromogenic in situ hybridization (CISH) was produced using a Probe Synthesis kit (Roche Diagnostics). The primer used to detect DNMT1 was designed using free software primer3, with reference to information provided by the National Center for Biotechnology Information (NCBI). The reference sequence was NG_028016.1. The forward and reverse primer sequences were GACCTCCTCCTCTGTTGCAG and AGAC CAGGGGTCACACAAAG, respectively. The PCR product (348 bp) was used as the CISH probe and labeled with DIG by the kit. CISH was performed using this probe, and detection was carried out using the GenPoint kit (Dako) in the same manner as mRNA detection. CISH was performed in 48 cases in the same manner as mRNA ISH.

Assessments and statistical analysis. Immunocytochemical staining of DNMT1 was considered positive when $\geq 20 \%$ of the tumor cells expressed the protein in the nucleus (6). The color
Table I. Correlation between protein expression levels and tumor development.

\begin{tabular}{lccc}
\hline $\begin{array}{l}\text { Protein } \\
\text { expression }\end{array}$ & Non-cancerous (n) & Cancerous (n) & P-value \\
\hline $\begin{array}{l}\text { hMLH1 } \\
\text { Positive }\end{array}$ & 28 & 26 & 0.0043 \\
Negative & 1 & 12 & \\
E-cadherin & & & \\
Positive & 26 & 28 & 0.13 \\
Negative & 3 & 10 & \\
DNMT1 & & & \\
Positive & 17 & 35 & 0.0023 \\
Negative & 12 & 3 & \\
\hline
\end{tabular}

DNMT1, DNA methyltransferase 1.

development of the cytoplasm was not taken into consideration for this determination. hMLH1 and E-cadherin were regarded as negative when $\geq 10 \%$ of the tumor cells in the membrane were attenuated. As for ISH, cases in which the cytoplasm in $\geq 10 \%$ of the tumor cells was stained were considered positive. Intra-nuclear signals of the DNMT1 gene in at least 20 nuclei per case were quantified and the average was calculated. Statistical analyses for associations were performed using the Student's t-test or the $\chi^{2}$ test. $\mathrm{P}<0.05$ was considered to indicate a statistically significant difference.

\section{Results}

Immunostaining. Immunostaining results showed that DNMT1 and hMLH1 proteins were expressed in the nucleus, whereas E-cadherin was expressed in the membrane (Fig. 1). The expression of DMNT1 was observed even in normal tissue, with $50 \%$ of normal tissues evaluated as positive. Positive cases increased with tumor development and $92 \%$ of the cases in the carcinoma group demonstrated positivity. Expression of hMLH1 in the nucleus was observed in all the cases of normal tissue, while attenuated cases increased with tumor development and $32 \%$ of the cases in the carcinoma group were negative. Similar findings were obtained for E-cadherin, with $26 \%$ of the cases in the carcinoma group evaluated as negative (Fig. 2).

Tumor development was significantly associated with the expression of DNMT1 and hMLH1 (Table I). In addition, the expression of DNMT1 was significantly correlated with the expression of hMLH1 and E-cadherin (Table II). However, no significant correlation was observed with the carcinoma group (Table III). In addition, there were no cases negative for hMLH1 or E-cadherin among the DNMT1-negative cases and none of the attenuated cases had hMLH1 and E-cadherin expression.

mRNA in situ hybridization. The expression of DNMT1 mRNA was examined using an ISH method (Fig. 3). DNMT1 mRNA was completely absent in all the normal cases, while only a few cases in the hyperplasia and atypical hyperplasia groups were positive. However, a high expression level was observed in carci- 

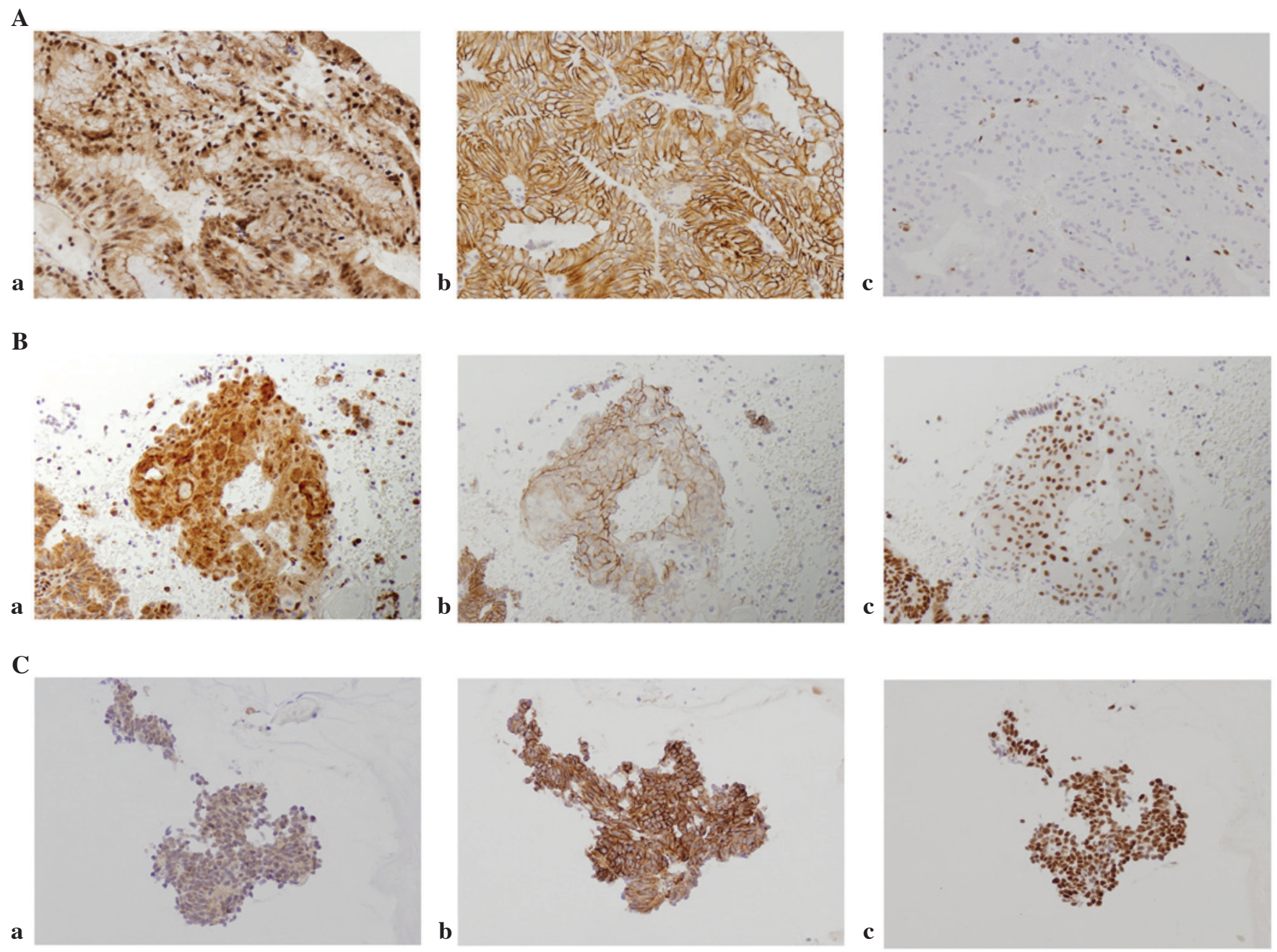

Figure 1. Protein expression in carcinoma cases. (A) a, DNA methyltransferase 1 (DNMT1)-positive; b, E-cadherin-positive and c, hMLH1-negative. (B) a, DNMT1-positive; b, E-cadherin-negative and c, hMLH1-positive. (C) a, DNMT1-negative; b, E-cadherin-positive and c, hMLH1-positive.

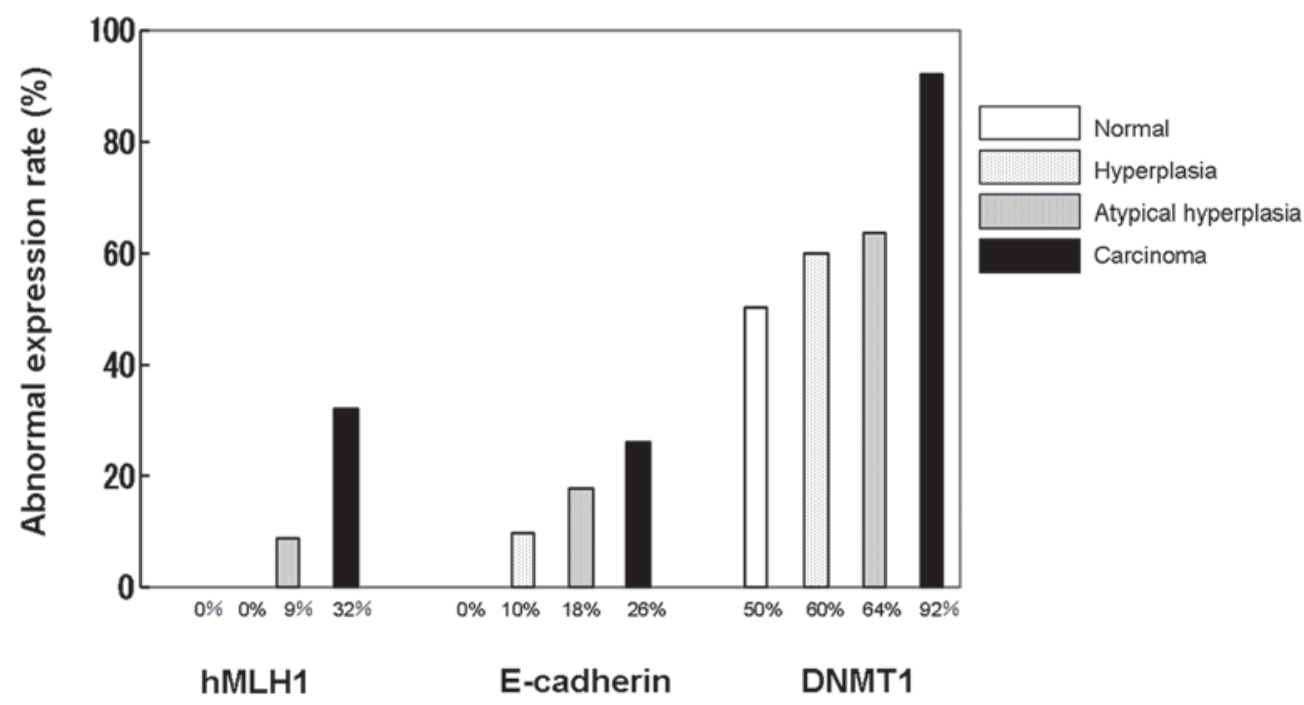

Figure 2. Rates of abnormal protein expression in normal, hyperplasia, atypical hyperplasia and carcinoma cases. DNMT1, DNA methyltransferase 1.

noma cases, $42 \%$ of which were positive (Fig. 4). In addition, a significant correlation between DNMT1 mRNA expression and attenuation of hMLH1 protein was observed (Table IV).
Chromogenic DNA in situ hybridization. DNMT1 gene amplification using the CISH method was also performed (Fig. 5) in each case, showing that the average number of signals increased 
A

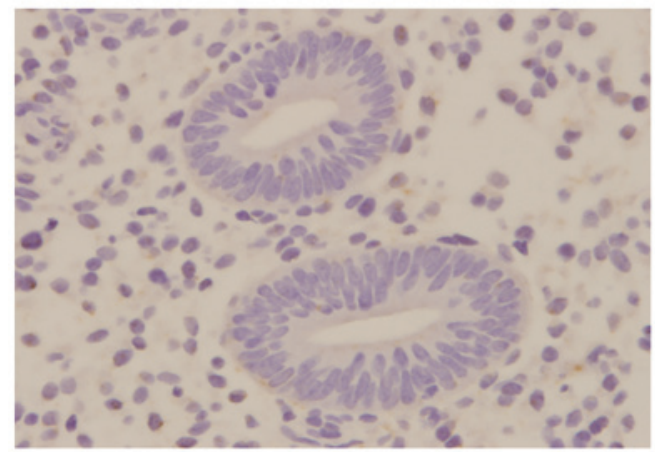

C

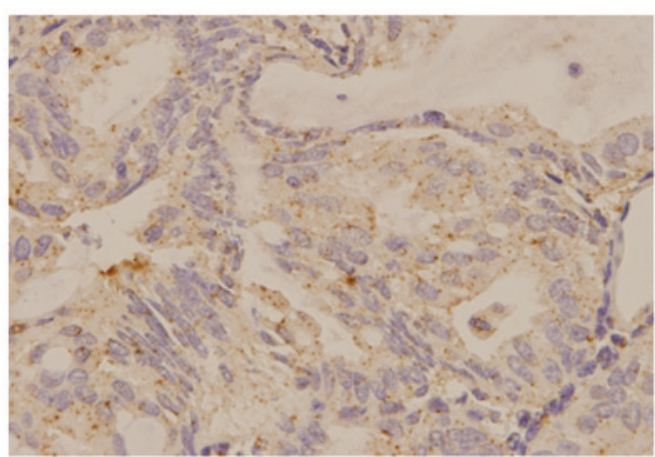

B

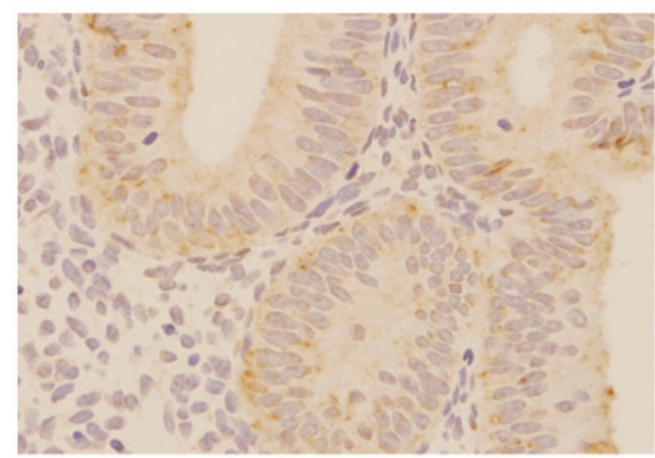

D

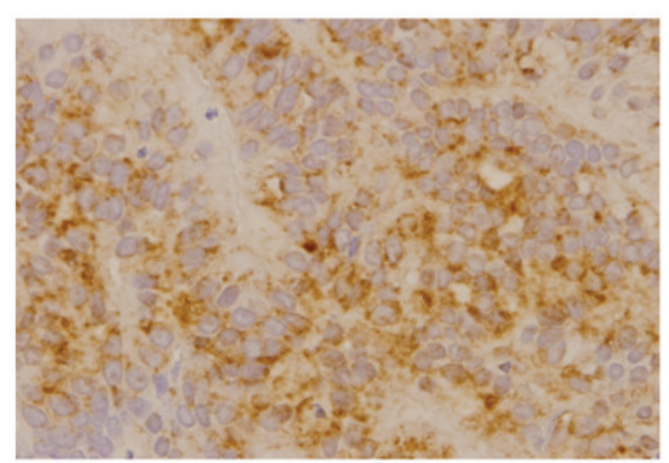

Figure 3. The expression of DNA methyltransferase 1 (DNMT1) mRNA. (A) Normal, (B) hyperplasia, (C) atypical hyperplasia and (D) carcinoma.

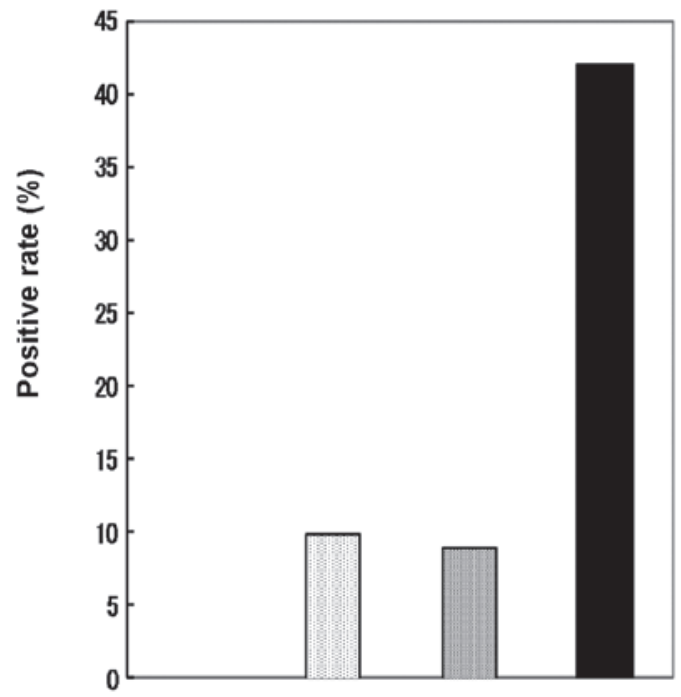

Positive rate

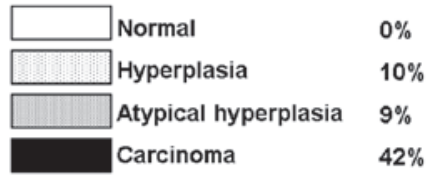

Figure 4. Correlation between DNA methyltransferase 1 (DNMT1) mRNA and tumor development.

A

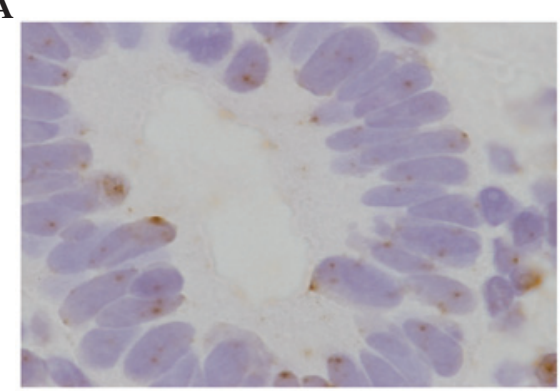

B

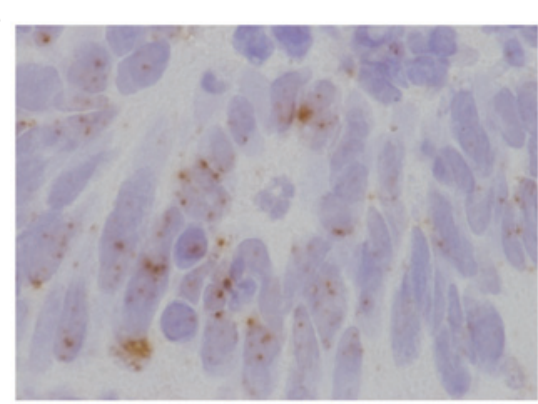

C

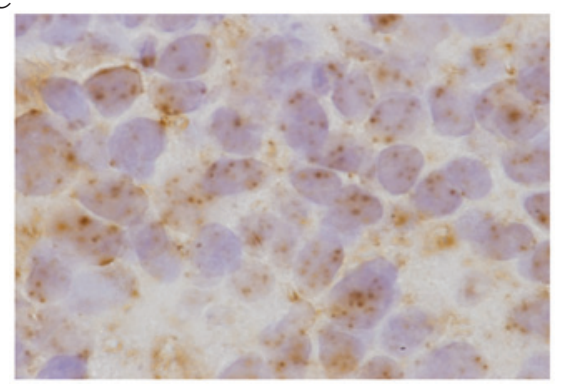

Figure 5. Gene amplification of DNA methyltransferase 1 (DNMT1) using the chromogenic in situ hybridization (CISH) method. (A) A normal case: signal count was 2.1, (B) a hyperplasia case: signal count was 2.3 and (C) a cancer case: signal count was 3.9. 
Table II. Correlation among the expression levels of the three examined proteins.

\begin{tabular}{|c|c|c|c|}
\hline \multirow{2}{*}{$\begin{array}{l}\text { Protein } \\
\text { expression }\end{array}$} & \multicolumn{3}{|c|}{ hMLH1 } \\
\hline & Positive & Negative & $\mathrm{P}$-value \\
\hline \multicolumn{4}{|l|}{ E-cadherin } \\
\hline Positive & 41 & 13 & 0.058 \\
\hline \multirow[t]{3}{*}{ Negative } & 13 & 0 & \\
\hline & \multicolumn{3}{|c|}{ hMLH1 } \\
\hline & Positive & Negative & P-value \\
\hline \multicolumn{4}{|l|}{ DNMT1 } \\
\hline Positive & 39 & 13 & 0.031 \\
\hline \multirow[t]{3}{*}{ Negative } & 15 & 0 & \\
\hline & \multicolumn{3}{|c|}{ E-cadherin } \\
\hline & Positive & Negative & P-value \\
\hline \multicolumn{4}{|l|}{ DNMT1 } \\
\hline Positive & 39 & 13 & 0.031 \\
\hline Negative & 15 & 0 & \\
\hline
\end{tabular}

DNMT1, DNA methyltransferase 1.
Table III. Correlation among the expression levels of the three examined proteins (carcinoma cases only).

\begin{tabular}{|c|c|c|c|}
\hline \multirow{2}{*}{$\begin{array}{l}\text { Protein } \\
\text { expression }\end{array}$} & \multicolumn{3}{|c|}{ hMLH1 } \\
\hline & Positive & Negative & P-value \\
\hline \multicolumn{4}{|l|}{ E-cadherin } \\
\hline Positive & 16 & 12 & 0.28 \\
\hline \multirow[t]{3}{*}{ Negative } & 10 & 0 & \\
\hline & \multicolumn{3}{|c|}{ hMLH1 } \\
\hline & Positive & Negative & $\mathrm{P}$-value \\
\hline \multicolumn{4}{|l|}{ DNMT1 } \\
\hline Positive & 23 & 12 & 0.22 \\
\hline \multirow[t]{3}{*}{ Negative } & 3 & 0 & \\
\hline & \multicolumn{3}{|c|}{ DNMT1 } \\
\hline & Positive & Negative & $\mathrm{P}$-value \\
\hline \multicolumn{4}{|l|}{ E-cadherin } \\
\hline Positive & 16 & 12 & 0.28 \\
\hline Negative & 10 & 0 & \\
\hline
\end{tabular}

DNMT1, DNA methyltransferase 1.

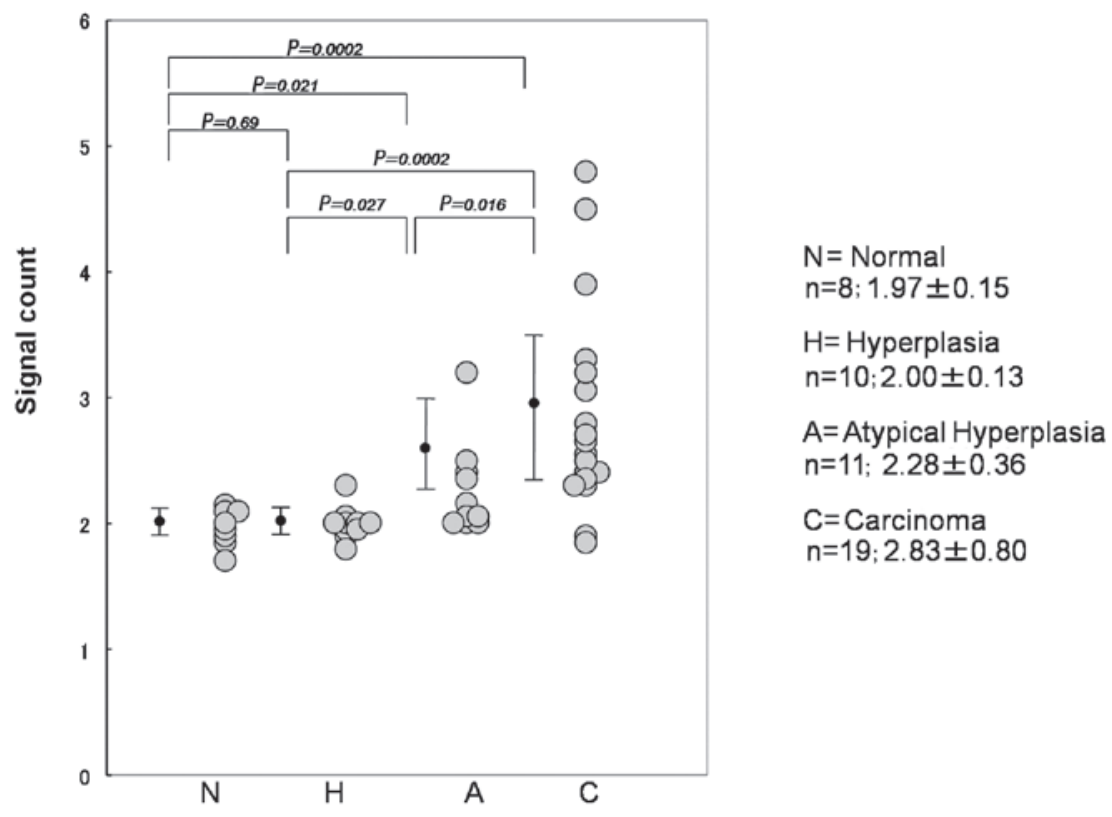

Figure 6. Correlation between gene amplification of DNA methyltransferase 1 (DNMT1) and tumor progression.

with tumor development. The average number in normal, hyperplasia, atypical hyperplasia and carcinoma cases was 1.97, 2.00, 2.28 and 2.83, respectively (Fig. 6). Furthermore, DNMT1 gene amplification was found to be correlated with the expression of DNMT1 protein (Table V).

\section{Discussion}

In a previous study, we investigated the expression of DNMT1, an important protein in the maintenance of methylation, in relation to the expression of hMLH1 and E-cadherin, which 
Table IV. Correlation between tumor development, protein expression and DNMT1 mRNA.

\begin{tabular}{lccc}
\hline & \multicolumn{3}{c}{ DNMT1 mRNA expression } \\
\cline { 2 - 4 } Protein expression & Positive & Negative & P-value \\
\hline Non-cancerous & 2 & 27 & 0.0082 \\
Cancerous & 8 & 11 & \\
hMLH1 & & & \\
$\quad$ Positive & 5 & 34 & 0.012 \\
$\quad$ Negative & 5 & 4 & \\
DNMT1 & & & \\
Positive & 8 & 26 & 0.7 \\
$\quad$ Negative & 2 & 12 & \\
E-cadherin & & & \\
Positive & 10 & 31 & 0.32 \\
Negative & 0 & 7 & \\
\hline
\end{tabular}

DNMT1, DNA methyltransferase 1.

Table V. Correlation between gene amplification of DNMT1 and protein expression levels.

\begin{tabular}{lrcc}
\hline $\begin{array}{l}\text { Protein } \\
\text { expression }\end{array}$ & $\mathrm{N}$ & Average of signals & P-value \\
\hline hMLH1 & & & \\
Positive & 39 & $2.34 \pm 0.66$ & 0.37 \\
Negative & 9 & $2.57 \pm 0.64$ & \\
E-cadherin & & & \\
Positive & 41 & $2.34 \pm 0.60$ & 0.30 \\
Negative & 7 & $2.63 \pm 0.92$ & \\
DNMT1 & & & 0.041 \\
Positive & 34 & $2.47 \pm 0.74$ & \\
Negative & 14 & $2.17 \pm 0.27$ & \\
mRNA & & & 0.10 \\
Positive & 10 & $2.81 \pm 0.91$ & \\
Negative & 38 & $2.28 \pm 0.53$ & \\
\hline
\end{tabular}

DNMT1, DNA methyltransferase 1.

is often observed in endometrioid carcinomas (6). In the present study, mRNA expression and gene amplification of DNMT1 were investigated, and results showed that they were increased with tumor development. These results suggest that DNMT1 mRNA expression and/or gene amplification may be associated with excessive methylation in endometrial carcinomas.

DNMT1 was initially cloned in 1988 (2). Methylation is regarded as indispensable for life in animals, as mice die following DNMT1 gene removal (7). DNMT1 is developed during mitosis and methylation of the same locus is maintained throughout mitosis by DNMT1. In cases of bladder cancer, it has been reported that DNMT1 is developed in precancerous tissue around the carcinoma (8). In addition, the expression of DNMT1 has also been reported in chronic hepatitis $(9,10)$ and ulcerative colitis (11). In the present study, DNMT1 expression was observed in half of the normal tissue samples, thus aberrant methylation may occur at a high frequency in the endometrium.

DNMT1 overexpression has been shown to be correlated with tumor development in a variety of types of malignant tumors, while DNMT1 expression in hepatoma (12) and pancreatic carcinoma (13) has been reported to be useful as an indicator of poor prognosis. In this study, the expression of DNMT1 was observed in most cases of endometrioid adenocarcinoma. Endometrial carcinomas are known to frequently occur in patients with Lynch syndrome, which is characterized by gene mutations such as hMLH1. None of the patients included in the study were confirmed to have Lynch syndrome, and most were thought to have sporadic cancer (14). Since DNMT1 was detected in most of the carcinoma cases included in the study, it is suggested that most of the tumors were developed by accumulation of methylation, unlike other types of tumors.

The attenuation of hMLH1 and E-cadherin in endometrial tissues was also investigated, and a correlation with DNMT1 expression was identified. Previous studies have shown that methylation of hMLH1 and E-cadherin occur at high frequency in endometrial cancer $(3,15)$. Therefore, one of the causes of the attenuation of hMLH1 and E-cadherin may be methylation of the promoter part by DNMT1. We re-examined this correlation in the carcinoma group, however, the correlation was not significant, possibly due to the low number of cases examined.

DNMT1 mRNA expression was investigated using the ISH method. The expression was low in normal, hyperplasia and atypical hyperplasia tissues, while it was significantly high in the carcinoma cases in which DNMT1 mRNA was thought to have developed in a constant manner. mRNA expression was also significantly associated with the attenuation of hMLH1, albeit not with the attenuation of E-cadherin. Regarding the cause of attenuation of E-cadherin, various reasons were considered. For example, Snail, which functions as an inhibiting factor, has been considered to have an effect in addition to methylation (16). However, we consider that most of the attenuation of hMLH1 is caused by methylation of the promoter part, thus, indicating a significant association.

Furthermore, the condition of DNMT1 gene amplification in endometrial tissues was investigated using the CISH method, which has been rarely reported. It was observed that the DNMT1 gene was slightly amplified in relation to tumor development. In carcinoma cases, 3 or 4 signals were typically observed in each nucleus, while there were no cases with extensive gene amplification up to $\sim 10$ to 20 -fold, as often observed in cases of breast cancer. We considered that the minor amplification of DNA might accompany carcinogenesis. Since DNMT1 expression was found to be associated with DNMT1 gene amplification, it is possible that it is strengthened by gene amplification.

It was previously reported that DNMT1 expression does not only occur with proliferative activity (8). In the present study, we confirmed that there was no significant correlation between the expression of DNMT1 and Ki-67, the latter of which is 
utilized as a marker of proliferative activity (data not shown). As yet, aberration of proliferative activity in cancer has not been elucidated in detail. However, activation of DNMT1 is expected to be induced by a mechanism that is different from cell growth.

In conclusion, our findings demonstrate that methylation is associated with carcinogenesis in the endometrium. Although DNMT1 protein is expressed in normal endometrial tissue, a constant expression of DNMT1 mRNA contributes to cancerization. DNMT1 gene amplification is associated with DNMT1 protein expression, although that is only one of the causes of DNMT1 activation in tumor development, with genetic activation in the upper streams of DNMT1 thought to be another. Additional studies are required to investigate this correlation.

\section{References}

1. Bestor T, Laudano A, Mattaliano R and Ingram V: Cloning and sequencing of a cDNA encoding DNA methyltransferase of mouse cells. The carboxyl-terminal domain of the mammalian enzymes is related to bacterial restriction methyltransferases. J Mol Biol 203: 971-983, 1988.

2. Etoh T, Kanai Y, Ushijima S, Nakagawa T, Nakanishi Y, Sasako M, Kitano S and Hirohashi S: Increased DNA methyltransferase 1 (DNMT1) protein expression correlates significantly with poorer tumor differentiation and frequent DNA hypermethylation of multiple $\mathrm{CpG}$ islands in gastric cancers. Am J Pathol 164: 689-699, 2004

3. Banno K, Yanokura M, Susumu N, Kawaguchi M, Hirao N, Hirasawa A, Tsukazaki K and Aoki D: Relationship of the aberrant DNA hypermethylation of cancer-related genes with carcinogenesis of endometrial cancer. Oncol Rep 16: 1189-1196, 2006.

4. Japan Society of Obstetrics and Gynecology: The General Rules for Clinical and Pathological Management of Uterine Corpus Cancer. 3rd edition. Kinbara Shuppan, Tokyo, 2012.

5. Mizuno S, Chijiwa T, Okamura T, Akashi K, Fukumaki Y, Niho Y and Sasaki H: Expression of DNA methyltransferases DNMT1, 3A, and 3B in normal hematopoiesis and in acute and chronic myelogenous leukemia. Blood 97: 1172-1179, 2001.

6. Liao X, Siu MK, Chan KY, Wong ES, Ngan HY, Chan QK, Li AS, Khoo US and Cheung AN: Hypermethylation of RAS effector related genes and DNA methyltransferase 1 expression in endometrial carcinogenesis. Int J Cancer 123: 296-302, 2008.
7. Li E, Bestor TH and Jaenisch R: Targeted mutation of the DNA methyltransferase gene results in embryonic lethality. Cell 69: 915-926, 1992.

8. Nakagawa T, Kanai Y, Saito Y, Kitamura T, Kakizoe T and Hirohashi S: Increased DNA methyltransferase 1 protein expression in human transitional cell carcinoma of the bladder. J Urol 170: 2463-2466, 2003.

9. Kondo Y, Kanai Y, Sakamoto M, Mizokami M, Ueda R and Hirohashi S: Genetic instability and aberrant DNA methylation in chronic hepatitis and cirrhosis - A comprehensive study of loss of heterozygosity and microsatellite instability at 39 loci and DNA hypermethylation on $8 \mathrm{CpG}$ islands in microdissected specimens from patients with hepatocellular carcinoma. Hepatology 32: 970-979, 2000.

10. Saito Y, Kanai Y, Sakamoto M, Saito H, Ishii H and Hirohashi S: Expression of mRNA for DNA methyltransferases and methyl-CpG-binding proteins and DNA methylation status on $\mathrm{CpG}$ islands and pericentromeric satellite regions during human hepatocarcinogenesis. Hepatology 33: 561-568, 2001.

11. Fujii S, Katake Y and Tanaka H: Increased expression of DNA methyltransferase-1 in non-neoplastic epithelium helps predict colorectal neoplasia risk in ulcerative colitis. Digestion 82: 179-186, 2010.

12. Saito Y, Kanai Y, Nakagawa T, Sakamoto M, Saito H, Ishii H and Hirohashi S: Increased protein expression of DNA methyltransferase (DNMT) 1 is significantly correlated with the malignant potential and poor prognosis of human hepatocellular carcinomas. Int J Cancer 105: 527-532, 2003.

13. Peng DF, Kanai Y, Sawada M, Ushijima S, Hiraoka N, Kosuge T and Hirohashi S: Increased DNA methyltransferase 1 (DNMT1) protein expression in precancerous conditions and ductal carcinomas of the pancreas. Cancer Sci 96: 403-408, 2005.

14. Hampel H, Frankel WL, Martin E, Arnold M, Khanduja K, Kuebler P, Nakagawa H, Sotamaa K, Prior TW, Westman J, Panescu J, Fix D, Lockman J, Comeras I and de la Chapelle A: Screening for Lynch syndrome (hereditary nonpolyposis colorectal cancer) among endometrial cancer patients. Cancer Res 66: 7810-7817, 2006.

15. Saito T, Nishimura M, YamasakiH and Kudo R:Hypermethylation in promoter region of E-cadherin gene is associated with tumor dedifferention and myometrial invasion in endometrial carcinoma. Cancer 97: 1002-1009, 2003.

16. Blechschmidt K, Kremmer E, Hollweck R, Mylonas I, Höfler H, Kremer M and Becker KF: The E-cadherin repressor snail plays a role in tumor progression of endometrioid adenocarcinomas. Diagn Mol Pathol 16: 222-228, 2007. 